in vivo $32: 1211-1216(2018)$

doi:10.21873/invivo.11366

\title{
Pathological Complete Response by S-1 Chemotherapy in Advanced Gastric Cancer
}

\author{
TSUTOMU NAMIKAWA ${ }^{1}$, NOBUKO ISHIDA ${ }^{1}$, SACHI TSUDA ${ }^{1}$, KAZUNE FUJISAWA ${ }^{1}$, \\ ERI MUNEKAGE ${ }^{1}$, JUN IWABU ${ }^{1}$, MASAYA MUNEKAGE ${ }^{1}$, SUNAO UEMURA $^{1}$, SHIGEHIRO TSUJII ${ }^{1}$, \\ HIROMICHI MAEDA ${ }^{2}$, HIROYUKI KITAGAWA ${ }^{1}$, MICHIYA KOBAYASHI ${ }^{2,3}$ and KAZUHIRO HANAZAKI ${ }^{1}$ \\ ${ }^{1}$ Department of Surgery, Kochi Medical School, Kochi, Japan; \\ ${ }^{2}$ Cancer Treatment Center, Kochi Medical School Hospital, Kochi, Japan; \\ ${ }^{3}$ Department of Human Health and Medical Sciences, Kochi Medical School, Kochi, Japan
}

\begin{abstract}
A pathological complete response ( $p C R$ ) to treatment for gastric cancer is a rare event, even when powerful treatment regimens are used. Herein, a case of 61year-old male referred to our hospital with advanced gastric cancer who achieved a $p C R$ following chemotherapy using $S-1$, and subsequently underwent total gastrectomy is reported. His initial esophagogastroduodenoscopy (EGD) revealed an irregular, nodular, ulcerated lesion in the upper third of the stomach that was analyzed by biopsy to be a moderately differentiated adenocarcinoma. Abdominal contrast-enhanced computed tomography (CT) showed gastric wall thickening and lymph node swelling in the perigastric area. The patient was clinically diagnosed with cT3N1M0, stage IIB advanced gastric cancer. The patient decided against curative surgery due to his work circumstances and was started on $S-1 \quad\left(80 \mathrm{mg} / \mathrm{m}^{2}\right)$ chemotherapy administered orally twice a day for 4 weeks, followed by 2 weeks of no chemotherapy. After four such courses of systemic S-1 chemotherapy, EGD showed a small, reddened lesion with aggregated, whitish lines. The gastric wall thickening and lymphadenopathy in the perigastric area were also reduced remarkably. The patient subsequently agreed to surgery, undergoing total gastrectomy with D2 lymphadenectomy. Gross examination of the surgically resected specimen showed a slightly erythrogenic, flat lesion
\end{abstract}

This article is freely accessible online.

Correspondence to: Tsutomu Namikawa, Department of Surgery, Kochi Medical School, Kohasu, Oko-cho, Nankoku, Kochi 7838505, Japan. Tel: +81 888802370, Fax: +81 888802371, e-mail: tsutomun@kochi-u.ac.jp

Key Words: Gastric cancer, complete response, chemotherapy, S-1, preoperative therapy. measuring $1.5 \times 1.0 \mathrm{~cm}$. Pathological examination of the resected specimen and harvested lymph nodes detected no malignant cells. The postoperative course was uneventful. The patient has continued to receive $S-1$ chemotherapy, with no evidence of recurrence at 4 months post-surgery. To the best of our knowledge, this is only the second case of a gastric cancer patient achieving a pCR by $S-1$ monotherapy reported in the English literature and indicates the potential adoption of curative resection after $S$ - 1 chemotherapy as a treatment strategy for advanced gastric cancer.

Gastric cancer is a health concern worldwide and the seventh leading cause of cancer-associated deaths $(1,2)$. Surgical resection with regional lymphadenectomy remains the most effective treatment for gastric cancer, with recent advances in systemic chemotherapy further boosting the efficacy of such resection $(3,4)$. Adjuvant chemotherapy prior to curative resection has been widely investigated in phase III settings to improve the outcome of patients with advanced gastric cancer, with a view to become a standard therapeutic strategy $(5,6)$. Neoadjuvant chemotherapy is also a promising strategy, with high rates of compliance for such an intensive regimen, low toxicity rates, high rate of chemotherapy takeup, and higher probabilities of avoiding unnecessary surgery compared to adjuvant chemotherapy (7).

While neoadjuvant chemotherapy brings the opportunity of significant tumor regression and downstaging, a pathological complete response (pCR), which means no viable tumor cells defined by histological evaluation criteria after preoperative therapy, is a rare event even if powerful regimens are used (4). Herein a case of advanced gastric cancer that achieved pCR following preoperative systemic chemotherapy using $\mathrm{S}-1$, which is an oral prodrug of fluorouracil combined with gimeracil and oteracil to reduce the toxic gastrointestinal effects of fluorouracil is reported. 

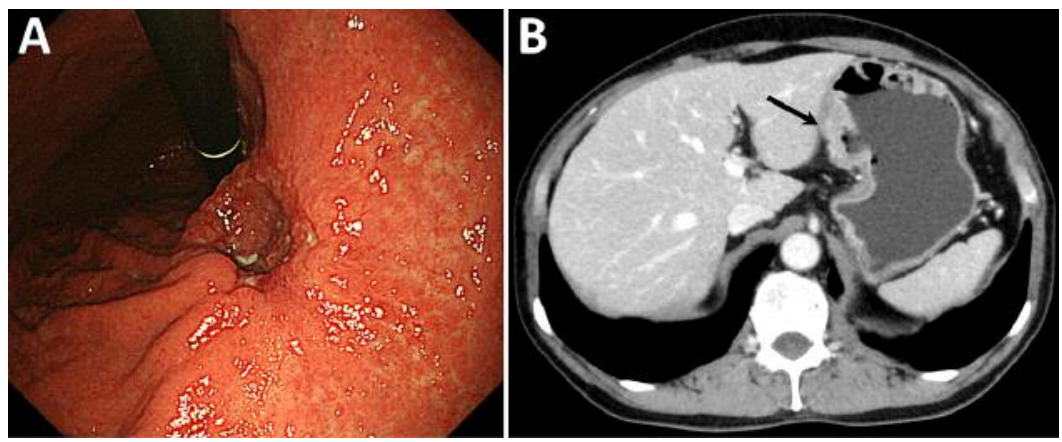

Figure 1. Initial esophagogastroduodenoscopy and computed tomography. Esophagogastroduodenoscopy showed an ulcerated lesion with central, irregular, depressed tumor in the lesser curvature side of the upper third of the stomach (A). Abdominal enhanced-computed tomography showed wall thickening with homogenous enhancement in the upper part of the stomach (arrow) and enlarged lymph nodes in the perigastric area (B).

\section{Case Report}

A 61-year-old Japanese man was referred to our hospital for further examination of gastric cancer diagnosed by medical check-up. His past medical history and family history were unremarkable. The laboratory findings, including serum carcinoembryonic antigen and cancer antigen 19-9, were just outside normal limits. Esophagogastroduodenoscopy (EGD) revealed a deep ulcerative tumor with a slightly elevated irregular border measuring approximately $5 \mathrm{~cm}$ in diameter in the lesser curvature side of the upper third of the stomach (Figure 1A). Abdominal contrast-enhanced computed tomography $(\mathrm{CT})$ revealed gastric wall thickening with homogeneous enhancement in the upper part of the stomach (Figure $1 \mathrm{~B}$, arrow), and enlarged lymph nodes in the perigastric area that suggested regional lymph nodes metastases. Histological analysis of a biopsy specimen from the tumor indicated a moderately differentiated adenocarcinoma (Figure 2).

Based on the above findings, the diagnosis was cT3N1M0, stage IIB gastric cancer according to the 8th International Union Against Cancer (UICC) TNM classification (8), and surgery was recommended to achieve curative resection. The patient rejected surgery due to his work circumstances, and thus $\mathrm{S}-1\left(80 \mathrm{mg} / \mathrm{m}^{2}\right)$ was administered orally twice a day for 4 weeks, followed by 2 weeks of no chemotherapy. After 4 such cycles of systemic chemotherapy using S-1, EGD showed a small, reddened lesion with aggregated, whitish lines (Figure 3A). A follow-up abdominal contrast-enhanced CT revealed remarkably reduced gastric wall thickening and shrinkage of the lymphadenopathy (Figure 3B). Subsequently, the patient accepted the surgical therapy, undergoing total gastrectomy and D2 lymphadenectomy followed by Roux-en-Y reconstruction according to the Japanese gastric cancer treatment guidelines (9).

Gross examination of the surgically resected specimen showed a superficial flat lesion on a slightly reddened mucosa measuring $1.5 \times 1.5 \mathrm{~cm}$ (Figure 4). Microscopic examination of the specimen revealed atrophy and fibrosis of the gastric mucosa in the lesion area, accompanied by mild inflammatory cell infiltration in the submucosal and subserosal layer. There was no clear invasion of atypical epithelial cells at any site (Figure 5). The histological evaluation criteria of tumor response after preoperative therapy was Grade 3 (complete response) according to the Japanese classification guidelines for gastric carcinoma (10). Tumor classification after preoperative chemotherapy was ypT0N0M0. The postoperative course was uneventful, and the patient was discharged on postoperative day 10 . The patient developed no adverse reactions during the chemotherapy or during the perioperative period. $\mathrm{He}$ continues to receive S-1 chemotherapy, and there has been no evidence of recurrence 4 months following the operation.

\section{Discussion}

A case of pCR following S-1 chemotherapy for advanced gastric cancer is presented. Although adjuvant S-1 chemotherapy or capecitabine plus oxaliplatin is a standard treatment for locally advanced gastric cancer, neoadjuvant chemotherapy followed by radical surgery is recommended by the NCCN as an initial therapy $(5,6,11)$. This intensive chemotherapy approach in the neoadjuvant setting, typically involving combination chemotherapy such as S-1 plus cisplatin, has induced not only high response rates, but also some sporadic pCRs in cases of locally advanced gastric cancer $(4,7,12,13)$. To the best of our knowledge, this is only the second case in the English literature of a pCR to S1 monotherapy in a patient with gastric cancer (Table I).

$\mathrm{S}-1$ is an oral anticancer drug based on biochemical modulation that combines the pro-fluorouracil drug tegafur, an inhibitor of dihydropyrimidine dehydrogenase, and potassium oxonate in a molar ratio of 1:0.4:1 (5). It is used 


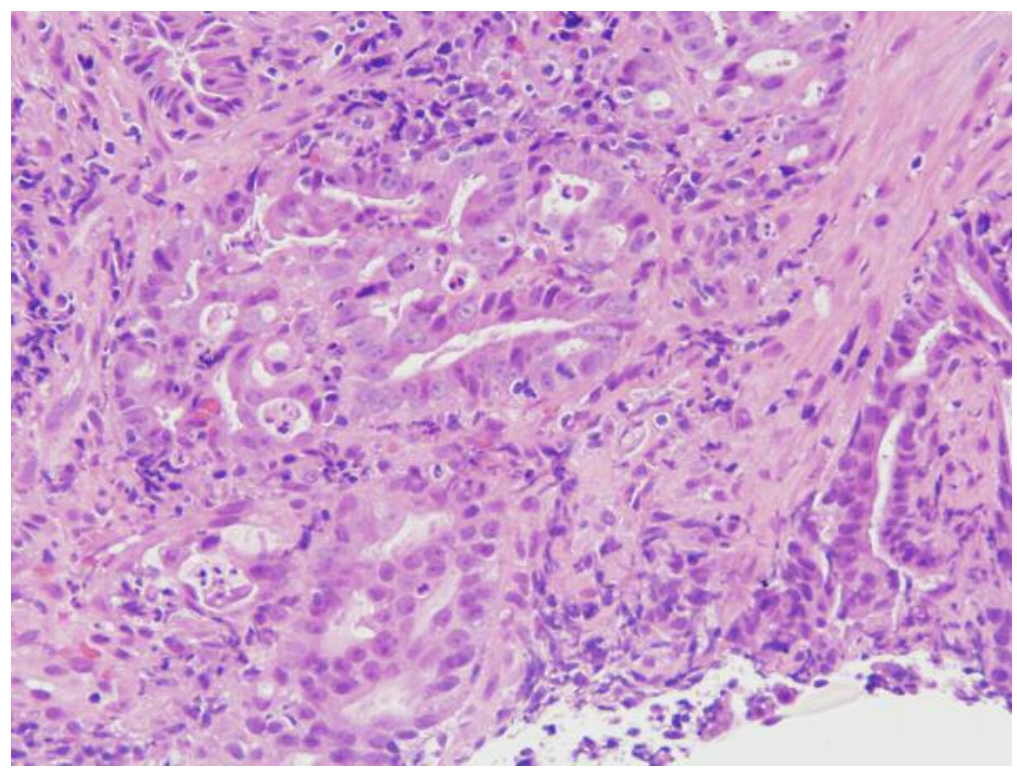

Figure 2. Histological findings of tumor biopsy specimen. The histological results indicated a moderately differentiated adenocarcinoma.
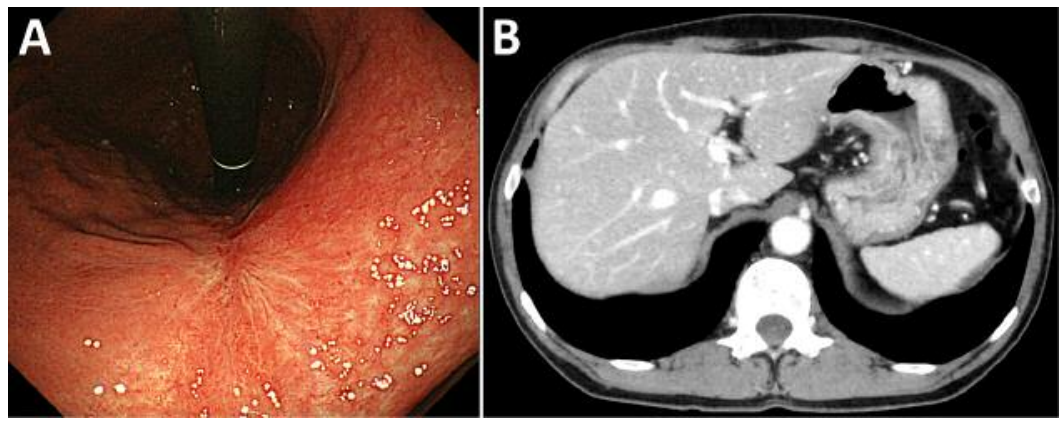

Figure 3. Esophagogastroduodenoscopy and computed tomography after systemic chemotherapy. Esophagogastroduodenoscopy showed a slightly elevated lesion with indistinct margins in the area of the original tumor $(A)$. Abdominal enhanced-computed tomography showed remarkably reduced gastric wall thickening and a remarkable reduction in lymph node swelling $(B)$.

Table I. Clinicopathological data for reported cases of gastric cancer achieving a pathological complete response by S-1 monotherapy.

\begin{tabular}{|c|c|c|c|c|c|c|c|c|c|c|}
\hline Author & Year & $\begin{array}{l}\text { Age } \\
(\mathrm{y})\end{array}$ & Gender & $\begin{array}{l}\text { Tumor } \\
\text { location }\end{array}$ & $\begin{array}{l}\text { Tumor size } \\
(\mathrm{cm})\end{array}$ & cStage & $\begin{array}{l}\text { Histologic } \\
\text { type }\end{array}$ & $\begin{array}{l}\text { Cycles of S-1 } \\
\text { chemotherapy }\end{array}$ & Operation & Outcome \\
\hline Mori (19) & 2006 & 78 & Female & L, Less & 4.2 & cT2N0M0, cStage IB & Diffuse & 1 & DG & ND \\
\hline Present case & 2018 & 61 & Male & U, Less & 5 & cT3N1M0, cStage IIB & Intestinal & 4 & TG & 4 months survival \\
\hline
\end{tabular}

U: Upper third of the stomach; L: lower third of the stomach; Less: lesser curvature; DG: distal gastrectomy; TG: total gastrectomy; cStage: clinical stage according to the 8th International Union Against Cancer (UICC) TNM classification; ND: not described.

commonly in combination with various anticancer agents to achieve greater responses for gastric cancer $(5,14)$. According to the Japanese gastric cancer treatment guidelines, systemic chemotherapy using S-1 plus cisplatin is recommended as the first-line treatment of unresectable advanced gastric cancer (9), although in patients over the age of $70, \mathrm{~S}-1$ plus cisplatin chemotherapy is discontinued more frequently than $\mathrm{S}-1$ alone, and repeated courses showed 


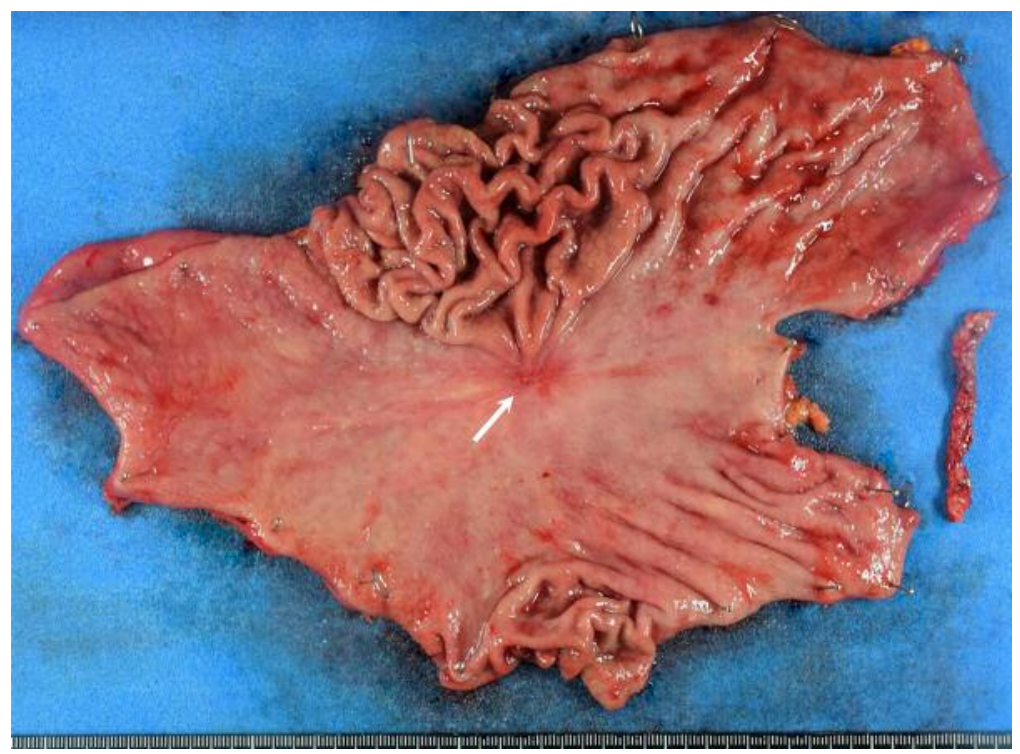

Figure 4. Macroscopic appearance of the surgically resected specimen. Gross examination of the resected specimen showed a superficial, flat, slightly reddened lesion in the mucosa measuring $1.5 \times 1.5 \mathrm{~cm}$ (arrow).

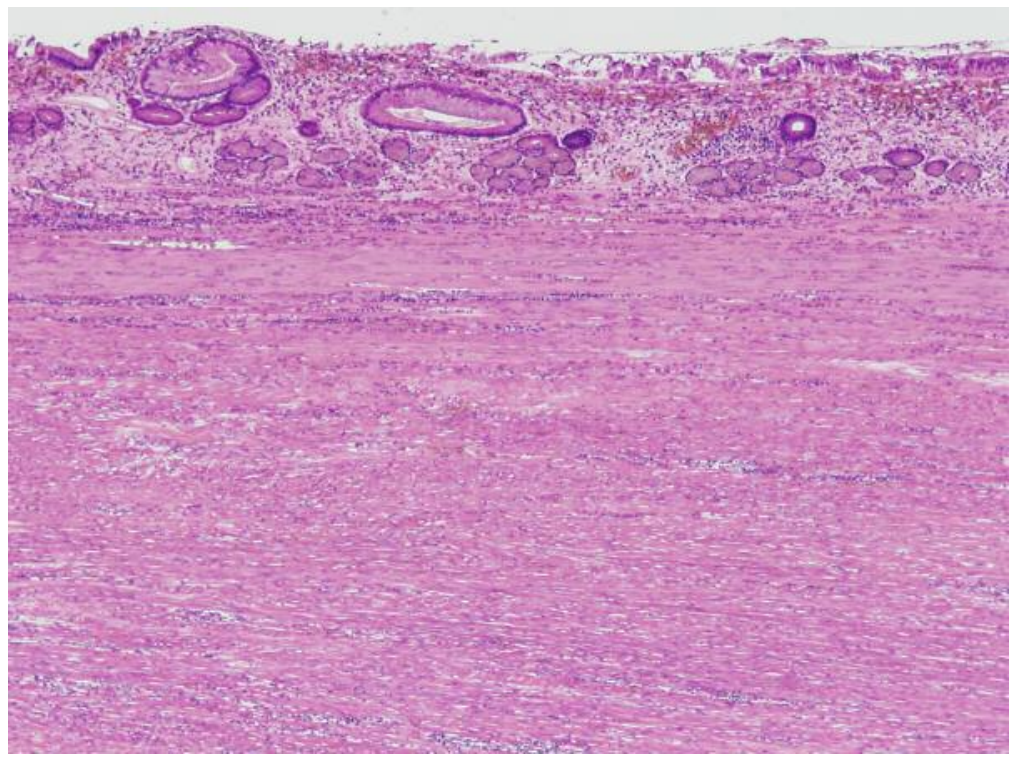

Figure 5. Histological findings of the surgically resected specimen. Histological analysis revealed an atrophy and fibrosis of the gastric mucosa in the lesion area, accompanied by inflammatory cell infiltration, and there was no clear infiltration of cancer cells at any site.

decreased efficacy (15). In such cases, S-1 monotherapy is a possible option, also because of its relatively minor side effects and high response efficiency $(16,17)$.

Previous studies reported clinical complete response rates of 1.1-2.1\% after chemotherapy using S-1 plus cisplatin for unresectable advanced or metastatic gastric cancer $(18,19)$.
In the present case, the initial indication of immediate radical surgery for a resectable gastric cancer was preceded by systemic S-1 monotherapy, according to the patient's wishes and our aim to minimize the potential adverse effects of chemotherapy that might be followed by surgery. Nevertheless, administering multiple cycles of preoperative 
chemotherapy remains controversial, because there is no clinical basis on which to establish the best timing of a potential curative resection during effective chemotherapy (4, 20). Yoshikawa et al. (13) demonstrated that long-term chemotherapy induced a high pCR rate without affecting the overall pathological response rate itself in a randomized phase II study. In the present case, four cycles of S-1 chemotherapy resulted in a postoperative diagnosis of $\mathrm{pCR}$. In the second study in English language reporting such a finding, Mori et al. (21) administered only one cycle comprising 2 weeks of oral S-1 administration to achieve a pCR. Thus, shorter periods of neoadjuvant chemotherapy than those used in our patient might still be effective in treating gastric cancer. On the other hand, a recent randomized phase II trial for macroscopically-resectable locally advanced gastric cancer demonstrated a pCR in $10 \%$ of patients after four cycles of neoadjuvant chemotherapy using S-1 plus cisplatin or paclitaxel plus cisplatin (13). Further studies including phase III trials are needed to select the most effective and suitable regimen and course for S-1 chemotherapy in patients with gastric cancer.

In conclusion, this case suggested that neoadjuvant chemotherapy using S-1 alone could be a potent strategy for selected patients with advanced gastric cancer and might contribute to improved treatment outcomes for these patients.

\section{Conflicts of Interest}

The Authors have no conflicts of interest to disclose regarding this study.

\section{References}

1 Fidler MM, Gupta S, Soerjomataram I, Ferlay J, SteliarovaFoucher E and Bray F: Cancer incidence and mortality among young adults aged 20-39 years worldwide in 2012: a populationbased study. Lancet Oncol 18(12): 1579-1589, 2017.

2 Allemani C and Coleman MP: Public health surveillance of cancer survival in the United States and worldwide: The contribution of the CONCORD programme. Cancer 123: 49774981, 2017

3 Nashimoto A, Akazawa K, Isobe Y, Miyashiro I, Katai H, Kodera Y, Tsujitani S, Seto Y, Furukawa H, Oda I, Ono H, Tanabe S and Kaminishi M: Gastric cancer treated in 2002 in Japan: 2009 annual report of the JGCA nationwide registry. Gastric Cancer 16(1): 1-27, 2013.

4 Cho H, Nakamura J, Asaumi Y, Yabusaki H, Sakon M, Takasu N, Kobayashi T, Aoki T, Shiraishi O, Kishimoto H, Nunobe S, Yanagisawa S, Suda T, Ueshima S, Matono S, Maruyama H, Tatsumi M, Seya T, Tanizawa Y and Yoshikawa T: Long-term survival outcomes of advanced gastric cancer patients who achieved a pathological complete response with neoadjuvant chemotherapy: a systematic review of the literature. Ann Surg Oncol 22(3): 787-792, 2015.

5 Sakuramoto S, Sasako M, Yamaguchi T, Kinoshita T, Fujii M, Nashimoto A, Furukawa H, Nakajima T, Ohashi Y, Imamura H,
Higashino M, Yamamura Y, Kurita A and Arai K: ACTS-GC Group. Adjuvant chemotherapy for gastric cancer with S-1, an oral fluoropyrimidine. N Engl J Med 357(18): 1810-1820, 2007.

6 Bang YJ, Kim YW, Yang HK, Chung HC, Park YK, Lee KH, Lee KW, Kim YH, Noh SI, Cho JY, Mok YJ, Kim YH, Ji J, Yeh TS, Button P, Sirzén F and Noh SH: CLASSIC trial investigators. Adjuvant capecitabine and oxaliplatin for gastric cancer after D2 gastrectomy (CLASSIC): a phase 3 open-label, randomised controlled trial. Lancet 379(9813): 315-321, 2012.

7 Yoshikawa T, Tanabe K, Nishikawa K, Ito Y, Matsui T, Kimura Y, Hirabayashi N, Mikata S, Iwahashi M, Fukushima R, Takiguchi N, Miyashiro I, Morita S, Miyashita Y, Tsuburaya A and Sakamoto J: Induction of a pathological complete response by four courses of neoadjuvant chemotherapy for gastric cancer: early results of the randomized phase II COMPASS trial. Ann Surg Oncol 21(1): 213-219, 2014.

8 Brierley JD, Gospodarowicz MK and Wittekind C (eds): "TNM classification of malignant tumours (8th Edition)." New York: John Wiley \& Sons, 2017.

9 Japanese Gastric Cancer Association: Japanese gastric cancer treatment guidelines 2014 (ver. 4). Gastric Cancer 20(1): 1-19, 2017.

10 Japanese Gastric Cancer Association: Japanese classification of gastric carcinoma: 3rd English edition. Gastric Cancer 14(2): 101-112, 2011.

11 Ajani JA, D’Amico TA, Almhanna K, Bentrem DJ, Chao J, Das P, Denlinger CS, Fanta P, Farjah F, Fuchs CS, Gerdes H, Gibson M, Glasgow RE, Hayman JA, Hochwald S, Hofstetter WL, Ilson DH, Jaroszewski D, Johung KL, Keswani RN, Kleinberg LR, Korn WM, Leong S, Linn C, Lockhart AC, Ly QP, Mulcahy MF, Orringer MB, Perry KA, Poultsides GA, Scott WJ, Strong VE, Washington MK, Weksler B, Willett CG, Wright CD, Zelman D, McMillian N and Sundar H: Gastric Cancer, Version 3.2016, NCCN Clinical Practice Guidelines in Oncology. J Natl Compr Canc Netw 14(10): 1286-1312, 2016.

12 Tada K, Etoh T, Shitomi Y, Ueda Y, Tojigamori M, Shiroshita H, Shiraishi $\mathrm{N}$ and Inomata $\mathrm{M}$ : A case of advanced gastric cancer achieved a pathological complete response by chemotherapy. Surg Case Rep 3(1): 68, 2017.

13 Yoshikawa T, Rino Y, Yukawa N, Oshima T, Tsuburaya A and Masuda M: Neoadjuvant chemotherapy for gastric cancer in Japan: a standing position by comparing with adjuvant chemotherapy. Surg Today 44(1): 11-21, 2014.

14 Namikawa T, Fukudome I, Ogawa M, Munekage E, Munekage M, Shiga M, Maeda H, Kitagawa H, Kobayashi M and Hanazaki $\mathrm{K}$ : Clinical efficacy of protein-bound polysaccharide $\mathrm{K}$ in patients with gastric cancer undergoing chemotherapy with an oral fluoropyrimidine (S-1). Eur J Surg Oncol 41(6): 795-800, 2015.

15 Makiyama A, Kunieda K, Noguchi M, Kajiwara T, Tamura T, Takeda K, Sugiyama J, Minashi K, Moriwaki T, Sugimoto N, Nagase M, Negoro Y, Tsuda T, Shimodaira H, Okano N, Tsuji A, Sakai D, Yanagihara K, Ueda S, Tamura S, Otsu S, Honda T, Matsushita Y, Okuno T, Kashiwada T, Nozaki A, Ebi M, Okuda H, Shimokawa M, Hironaka S, Hyodo I, Baba E, Boku N, Muro K and Esaki T: First-line chemotherapy with S-1 alone or S-1 plus cisplatin for elderly patients with advanced gastric cancer: a multicenter propensity score matched study. Gastric Cancer, 2018. doi: 10.1007/s10120-018-0797-y. [Epub ahead of print] 
16 Namikawa T, Munekage E, Maeda H, Kitagawa H, Kobayashi $\mathrm{M}$ and Hanazaki K: Feasibility study of supportive care using lafutidine, a histamine $\mathrm{H} 2$ receptor antagonist, to prevent gastrointestinal toxicity during chemotherapy for gastric cancer. Anticancer Res 34(12): 7297-7301, 2014.

17 Iwabu J, Namikawa T, Tsuda S, Kitagawa H, Kobayashi M and Hanazaki K: Successful distal gastrectomy for gastric cancer with Child-Pugh class B alcoholic liver cirrhosis. Anticancer Res 38(5): 3085-3087, 2018.

18 Koizumi W, Narahara H, Hara T, Takagane A, Akiya T, Takagi M, Miyashita K, Nishizaki T, Kobayashi O, Takiyama W, Toh Y, Nagaie T, Takagi S, Yamamura Y, Yanaoka K, Orita $H$ and Takeuchi M: S-1 plus cisplatin versus S-1 alone for first-line treatment of advanced gastric cancer (SPIRITS trial): a phase III trial. Lancet Oncol 9(3): 215-221, 2008.

19 Iwasaki Y, Sasako M, Yamamoto S, Nakamura K, Sano T, Katai $\mathrm{H}$, Tsujinaka T, Nashimoto A, Fukushima $\mathrm{N}$ and Tsuburaya A: Gastric Cancer Surgical Study Group of Japan Clinical
Oncology Group. Phase II study of preoperative chemotherapy with S-1 and cisplatin followed by gastrectomy for clinically resectable type 4 and large type 3 gastric cancers (JCOG0210). J Surg Oncol 107(7): 741-745, 2013.

20 Liu Y, Zhang KC, Huang XH, Xi HQ, Gao YH, Liang WQ, Wang XX and Chen L: Timing of surgery after neoadjuvant chemotherapy for gastric cancer: Impact on outcomes. World J Gastroenterol 24(2): 257-265, 2018.

21 Mori S, Kishimoto H, Tauchi K and Higuchi K: Histological complete response in advanced gastric cancer after 2 weeks of S-1 administration as neoadjuvant chemotherapy. Gastric Cancer 9(2): 136-139, 2006.

Received April 24, 2018

Revised May 29, 2018

Accepted June 4, 2018 